\title{
The nexus between Management and Information Technology \\ - attitudes and influence of the professional bodies
}

\author{
P. Juliff \\ School of Management Information Systems \\ Deakin University, Burwood 3125 \\ Australia \\ Tel : +61392446266 \\ Fax : +61392446520 \\ E-mail :pjuliff@deakin.edu.au
}

\begin{abstract}
In examining the respective needs for managers to understand information technology (IT) and for IT professionals to understand management, it would seem reasonable to look at the publicly expressed attitudes of professional societies representing those two groups of people. The two professions chosen, accounting and computing, are both active in their attempts to influence the curriculum in tertiary institutions preparing candidates for their prospective membership. It is the aim of this paper to examine the academic requirements for initial and continuing membership of these professions and to see what inferences we might draw in relation to their perception of their members' need for knowledge of the other's discipline.
\end{abstract}

Keywords

Management, information systems, professional bodies, education

\section{INFORMATION MANAGEMENT}

\section{Information as an asset}

Every organisation, large or small, corporate or private, profit seeking or not, relies on information to undertake its daily tasks and achieve its goals. Indeed, this information is the organisation's single most important resource. Unlike stock, premises or even people, 
information is the only asset which cannot be replaced from the marketplace in the event of its loss or destruction.

The increased recognition of the importance of people as an asset of an organisation has led, over the past two decades, to the increased recognition of the importance of the personnel management function. We have seen the acceptance of the Human Resources Manager as a key participant in the management team. Most of us can remember when such a role would have been designated as a Staff Clerk and the major responsibility would have been one of reactively recruiting for vacancies to the specification of the section in which the vacancy occurred. By contrast, today's Human Resources Manager is expected to be proactive in managing staffing profiles, providing for long-term training and promotion plans and for advising on the myriad complexities of legal and financial implications of staff employment. That is, the management of people is recognised as being too important to be done by anybody other than a qualified expert.

If this has happened for the management of people, why have we not seen a similar change in the role of those who manage an even more important asset, information? There are very few corporate boardrooms comprising members who have come through the channel of information technology. In nautical terms, the information technologist is still seen as managing the boiler room rather than being on the bridge.

\section{Information management vs information husbandry}

There is an old aphorism which states :

The information you can get is not the information you want.

The information you want is not the information you need.

The information you need is not the information you can get.

We have seen the progressive labelling of computer-based systems from Electronic Data Processing Systems, through Management Information Systems and Decision Support Systems to Executive Information Systems. In many instances, it is the name rather than the nature of the operation which has changed. General management has often become disillusioned with its IT facility and innumerable cases are quoted of corporate dissatisfaction with the value added to an organisation by its IT function. The US magazine Computerworld published Andersen Consulting's report in 1991 which stated that of the 200 CEOs surveyed among the Fortune $1000,75 \%$ were of the opinion that corporate information systems were the key to competitive advantage. Two years later, the same sources reported that over $80 \%$ of senior executives in those organisations ranked the return on IT investment as "average" or "minimal".

Whose fault is this apparent gross under-achievement in IT potential? It would seem that we are led to several possible conclusions :

- management is unable to avail itself of the information provided by its information system, and/or

- the information system is not providing the information required at the time and place of its requirement, and/or

- there is considerable difficulty in specifying the management information needed over an extended period in a dynamic marketplace.

The first two of these may be blamed on the lack of expertise of the professionals concerned and, no doubt, are present in a number of cases. The third, however, is systemic and points out the need for cooperation between IT and general management and an understanding of 
each other's discipline. It is also arguably the most cogent reason for the emergence of an Information Manager.

There has been much name calling between general management and technology management over a period of thirty years. General management accuses IT personnel of speaking a language, both figuratively and literally, which they do not understand. The technologists, in their turn, complain that management at its various levels is vague in its requirements, constant in its changes of directions and priorities and capable of suggestions only after implementation of what is then claimed to be a deficient application.

The IT profession has been constant in its self-flagellation and breast-beating in its searching to narrow this gap. The same evidence of goodwill and effort has, in the past, not been shown by management. As evidence of this historical attitude, it is informative to examine the respective requirements of professional bodies associated with IT and business education :

- The Australian Computer Society has only ever required approximately $33 \%$ of an IT course to be computing related in order to achieve its highest level of professional accreditation. That is, the IT profession has acknowledged that as much as two thirds of a computing degree may be profitably spent on acquiring a knowledge of the domain in which the graduate is going to work.

- The Australian Society of Certified Practising Accountants had historically used a guideline that only $5 \%$ of a business degree needed to be spent studying information technology. This equates, in most business degrees, to one (necessarily introductory) unit in a 24-unit degree program. This sat oddly with the accountants' often expressed claim that they should be seen as custodians of corporate information bases.

If information is such an important asset to a corporation, it must be managed by professionals. The same approach to this exercise must be taken as has been taken to the management of personnel. The terms "management" and "husbandry" are contrasted in the heading of this paragraph. While there may be little difference between their dictionary definitions, husbandry is usually seen as reactive rather than proactive. It suggests actions such as conservation, keeping from harm, shielding from inclement surroundings. Much of what passes for information management is merely information husbandry. This is particularly true when the task is assigned to an IT manager who is primarily seen as a technologist. It is the job of that manager to ensure that the information is not lost, is kept clear of (literally) fire and flood, is there to be looked at when required, is kept free of bugs and viruses. All of this begs the question of whether the information has sufficient inherent value to be worth all of this effort. Unless this value is present, the trouble taken in husbanding the information will not be translatable into an effect on the goals of its owner organisation.

Effective information management, as opposed to husbandry, implies a proactive process. It implies that its manager is not merely a custodian but one who is able to make an active contribution to the decision making processes involved in establishing its content, format, accessibility and processing. To be able to do this, requires knowledge of both the management process and the process of building and maintaining information systems. 


\section{PROFESSIONAL CURRICULA}

\section{The role of the professional bodies}

The accounting profession in Australia provides a significant proportion of those people who aspire to managerial positions. It is also a profession which has a highly controlled and commonly accepted body of knowledge on a worldwide basis. The curriculum taught in Australian universities preparing entrants to the profession is closely monitored and largely controlled by the two accounting professional bodies - The Australian Society of Certified Practising Accountants (ASCPA) and The Institute of Chartered Accountants in Australia (ICAA). Membership of the ASCPA is currently in the vicinity of 77,000 and that of the ICAA is approximately 27,300 .

The professional society for information technology (IT) practitioners in Australia is the Australian Computer Society (ACS). Like the ASCPA and ICAA, the ACS also accredits tertiary academic programs and prescribes them in terms of areas of study and volume of IT content if they are to qualify graduates for membership of the Society. The ACS also conducts its own examinations for Australian and overseas candidates for membership. These examinations cover the minimum body of knowledge deemed necessary for admission to the ACS. The membership of the ACS numbers around 15,000.

These professional bodies have a variety of objectives, in large part able to be summarised as:

- internal - benefits for the members themselves in terms of ongoing professional development and support, and

- external - providing a visible interface between the practitioners and the general public and presenting an argument to the public that their members represent a better choice than nonmembers because of their monitored level of knowledge and adherence to a code of practice and professional ethics and behaviour.

\section{Accounting curriculum content}

Less than ten years ago, the tertiary course content prescribed by the ASCPA and ICAA related specifically to the traditional disciplines of financial and management accounting, economics, auditing, taxation, and the law relating to companies and commerce. The major volume of a business qualification as needed to satisfy the membership requirements of the accounting societies had to be provided from these areas. That is no longer the case. Business graduates may now choose between specialising in taxation, auditing or information technology and still satisfy ASCPA and ICAA entry requirements. There is a requirement, however, for taxation and auditing specialisations to have been completed if the candidate wishes to obtain a CPA endorsement. There is also a prescribed minimum IT content in any tertiary qualification leading to membership of the ASCPA and ICAA. In practice, however, this usually equates with only one specialist IT unit within a 24-unit degree programme. Over and above this specialist unit, however, it would be expected that there would be threads of IT exposure wound through much of the traditional curriculum.

In December 1995, the Education Committee of the International Federation of Accountants (IFAC) issued an International Education Guideline titled 'Information Technology in the Accounting Curriculum". To paraphrase its introduction, it points out that: 
- inexpensive hardware and communication facilities, coupled with powerful and userfriendly system development software have meant that IT has become available to enterprises of all types and sizes;

- converging technologies are integrating electronic mail, electronic commerce and electronic funds transfers and thereby changing the manner of businesses' operations;

- there have emerged new system development techniques, intelligent support systems and processes such as business re-engineering which must become familiar to those in decisionmaking positions within organisations.

In particular, IFAC directs that, prior to qualification, all accountants must have a general level of knowledge of the following areas :

- IT concepts for business systems

- general systems concepts, management uses of information, hardware, software, data organisation and access, networks and transaction processing applications.

- Internal control in computer-based business systems

- risk assessment and control objectives, environment, activities and monitoring.

- Development standards and practices for business systems

- the role of information within organisations, system acquisition and development processes.

- Management of IT adoption, implementation and use

- strategic, administrative and operational issues, management of development and maintenance.

- Evaluation of computer-based business systems

- legal, ethical, audit and control standards and computer-assisted auditing.

The conclusion which must be drawn from this is that the accounting profession has taken seriously the integration of IT and business/management practices and has begun to dictate that graduates must have the relevant knowledge prior to their graduation.

\section{IT curriculum content}

The ACS is currently revising its core body of knowledge for IT professionals. In addition, a consortium of representatives from the Association for Computing Machinery (ACM), the Association for Information Systems (AIS) and the Data Processing Management Association (DPMA) together with a selection of American academics and members of other co-operating IT organisations have released in May 1995 a 'Model Curriculum and Guidelines for Undergraduate Degree Programs in Information Systems' (IS95). The document takes some pains to distinguish the discipline of Information Systems (IS) from that of Computer Science. The IS function is seen as 'having a broad responsibility to develop, implement and manage an infrastructure of information technology....IT is pervasive in all organisation functions. It is used by accounting, finance, marketing, production, etc.'

Before elaborating at length on the specifics of the IS content, the Model Curriculum specifies that prerequisite topics include :

- Communications skills - written and oral.

- Mathematics and statistics - basic statistics, discrete maths.

- Business core - 'The cross functional nature of systems requires knowledge in the areas of marketing, finance, accounting, production, distribution and human resources".

- Other - macro and micro economics, internationalisation of business. 
It is recommended that 8 to 10 units of an undergraduate course be devoted to the IS content, representing between one third and one half of the undergraduate program. Within the specified body of computing knowledge there are units on Organisational Behaviour, Managing the Process of Change, Legal and Ethical Issues, Project Management and Systems Operation and Maintenance. While these are no doubt intended to be highly slanted towards IS, they are fields which have a managerial flavour to them.

The ACS Core Body of Knowledge has no specific reference to areas outside the IT discipline. Once again, however, it is anticipated that the IT content will comprise between at least one third to one half of the total curriculum of an undergraduate degree.

\section{PROFESSIONAL ACCREDITATION}

\section{Course accreditation}

Both the accounting bodies and the ACS are involved in accrediting tertiary academic courses. Accreditation of a course means that a graduate is eligible for a level of membership of the society concerned. In the case of both professions, the factors influencing accreditation are varied and include :

- the curriculum comprising the course, including both the academic content and the percentage of the course,

- the academic standing of the conducting institution, and

- the number and calibre of the teaching staff in the professional area.

The accreditation procedure is both a quality assurance agent and an agent for conservatism. Fear of the withdrawal of accreditation from a course is more or less threatening depending on the institution's perception of the importance of that accreditation to prospective students. It would be fair to say that accreditation is far more important to accounting courses than to IT courses. Membership of one of the accounting societies is generally accepted as a necessary condition for employment within the profession. This necessity is achieved largely through peer pressure and public expectation rather than through any legislative requirement. Membership of the ACS, however, is by no means a requirement for employment in an IT capacity.

In terms of using an accreditation process to produce a homogeneous body of practitioners with a shared perception of themselves as professionals, it is interesting to note that :

- whereas the ACS would not fail to accredit an IT course which had no management content, the accounting bodies would fail to accredit business courses which had an insufficient IT content;

- the ACS requires only a minimum of around $35 \%$ of IT content in its accredited courses, whereas the accounting bodies have recommended that a minimum of $60 \%$ of accredited courses must be either within an accounting major or be business related and that a minimum of $25 \%$ must be available to be taken in non-business studies.

The accounting bodies have also specified that they would prefer the IT content integrated within the general business content of a degree course rather than taught as separate, technically-oriented units. This has led to a number of business schools setting up IT specialisations within their own faculty. Almost invariably, on the other hand, IT courses are designed so that the IT content is presented by IT specialists and the non-IT content is 
delivered by other faculties. This has the inevitable effect of students perceiving that non-IT material is "foreign" to their course and, therefore, not really relevant.

\section{Post-graduation requirements}

It is common practice for professional bodies to require their members to acquire and maintain additional professional skills after graduation. The ICAA has a Professional Year (PY) program which is compulsory for becoming a Chartered Accountant. The program consists of four compulsory units in Taxation, Accounting and Ethics plus an additional unit to be chosen from five electives, one of which is Advanced Information Technology. This unit has been offered by the ICAA since 1994 and currently has in the order of 100 enrolments per year. The areas covered in this unit include :

- Strategic Planning

The role of information in business; the inter-relationship of IT strategic plans with business strategy; strategic planning issues.

- Applications

Business systems - generic and industry specific; support systems - decision support systems, knowledge based systems, executive information systems.

- Information systems delivery

Systems development methodologies; analysis and design; acquisition; software quality and development; system implementation.

- IT management

Project, operations and data management; security, audit and control; legal and ethical issues.

- Business data communications

Telecommunications; networks; electronic commerce.

The ICAA has an IT Chapter whose purpose is to raise the level of knowledge of and exposure to information technology applied to business. The Chapter produces a quarterly publication for its membership of around 3,000 Australia-wide. The ICAA also requires its members to undertake 40 hours per year of professional development training. IT is one of the accredited activities within this program and some IT component is compulsory for members of the IT Chapter.

The ASCPA has a similar operation to that of the ICAA. In order to qualify as a Certified Practising Accountant (CPA), graduates must have undertaken a number of specified units in their degree. A recent development, however, has allowed these units to include an "approved alternative Associate sequence" in management information systems. This may be substituted for one of the more traditional accounting areas of taxation, auditing and company law. Upon completion of an approved degree, a CPA must undertake further units including compulsory studies in financial reporting and professional practice and a selection of three out of seven optional units which include the Management of Information Systems. In order for CPAs to retain their status, they must attend a minimum of 60 hours structured professional development over each three year period. This activity may include IT courses relevant to the professional needs of the member concerned.

The ACS has no compulsory program required of its members for professional updating of expertise and knowledge. The Society has two voluntary schemes which members may pursue to enhance the currency of their knowledge : 
- Practising Computer Professional

ACS members are required to attend 36 hours of professional development activity each year. While this activity is not required to be exclusively involved with IT technology, there is a strong presumption that such will be the case.

- Certification Program

ACS members may undertake a formal examination process involving two compulsory papers and one of five optional units, each unit consisting of two papers. The papers address the areas of :

- compulsory papers : IT Trends and Business, Legal and Ethical Issues;

- optional units : Applications Planning, Project Management, Systems Integration, IT Management and Data Communications.

At present, of the 15,000 ACS members, approximately 1,500 are currently eligible for PCP rating and although 500 members are currently undertaking the Certification Program, only 31 have completed it as at this date. Within the Certification program, the IT Management and Project Management units may be regarded as having a managerial flavour, but they are highly focused on the IT activity.

\section{The professions' self image}

The International Federation of Accountants' Educational Guideline sees the role of an accountant with regard to information technology as being one of several facets :

- Manager of IT - needing the conceptual understanding of strategic considerations in IT development, administrative and operational issues, financial control over IT, system acquisition, development and implementation, plus the management of system maintenance and change and of end-user computing.

- Designer of IT - needing the knowledge of the basic steps to be followed in the design of IT systems such as the role of information in organisation design and behaviour, internal control practices, system design techniques and the various activities involved with the typical system development life cycle.

- Evaluator of IT - covering the evaluation of IT efficiency, effectiveness and economy of use, compliance with management policy, statutes and regulations, internal control and the fairness, accuracy and completeness of records.

As an aside, the Canadian Association of Certified General Accountants expects all of its members to have achieved a high level of IT expertise, including :

- practical and technical knowledge of the computer as a management problem-solving tool,

- the ability to participate in the design and control of complex information systems,

- the ability to adapt to and manage technological change , and

- proficiency in the application of computers to problem analysis and decision making.

By way of contrast, in the IS95 guidelines one of the characteristics of IT graduates is specified as :

- Management - 'the ability to establish project goals consistent with organisational goals; to specify, gather deploy, monitor and direct resources and activities and to apply concepts of continuous quality improvement'.

While there is further amplification of the role of specifically managing the IS function itself, there is no attempt to suggest that the IT graduate need to be further immersed in general management principles. 
In the arena of IT studies, the IS curricula is inclined to be more extroverted than is that for computer science, computer systems engineering and software engineering. These latter three disciplines will typically prescribe upwards of $80 \%$ of all studies to be undertaken within their own field, leaving very little room (and, generally, even less encouragement) for students to pursue broadening studies in business or management. At this date, an Australian university is instituting an undergraduate degree in Information Technology comprising 24 academic subjects of which 23 may be taken in an IT discipline.

Because of the much larger conformity to standards among accounting courses as compared to IT courses, there is a correspondingly larger homogeneity among accounting professionals themselves. The converse of this situation is either the greatest strength or the greatest weakness of the IT profession. IT professionals are traditionally drawn from a wide body of backgrounds, only some of whom have acquired a conventional IT tertiary qualification as accredited by the ACS. This works towards a diverse body of knowledge, experience and expertise among IT practitioners. It also makes for a very difficult task in attempting to have adopted a consistently accepted code of ethics and professional practice. Indeed, the most serious drawback of this situation is that it militates against IT employees considering themselves to be professionals in the true sense of that term. Most would see themselves as being closer to the technology than to the corporate ethos. Studies of employment patterns among IT professionals have consistently concluded that they tend to migrate to new technological challenges rather than to identify themselves with a current employer and to then seek to rise to a position of some corporate management responsibility.

\section{CONCLUSIONS}

\section{So, what conclusions may we draw?}

In considering the expressed and implied positions of the accounting and computing professions, I would suggest the following observations :

- each profession openly encourages its members' familiarity with the disciplines of the other;

- the accountants are far more serious about making an inroad into technology than are the computing professionals in learning financial and management skills;

- information technology is becoming more user-friendly, less arcane, requiring fewer 'rocket scientist' personnel to manage it;

- management is becoming more complex as organisations diversify and internationalise;

- it will become easier for managers to understand and control technology than it will be for technologists to influence management.

If information management grows to assume the same acknowledged importance as personnel management, it will spawn a professional group of information managers. This group will need to know more about management than about technology. Its members will need to seek acceptance more by fellow managers than by fellow technologists.

By their narrow focus on technology, IT professionals will continue to paint themselves into a career corner. By contrast, professionals who have come from a business discipline and see themselves as potential managers have a more structured framework in which to come to terms with what they need to know to manage technology. 
The ranks of the information managers of the future are more likely to be drawn from management than from technologists. There are serious implications here for developers of academic IT curricula. There is also very little evidence to suggest that this message will be heeded in the foreseeable future.

\section{REFERENCES}

Major documents referred to :

Education Committee of the International Federation of Accountants (IFAC) : (1995) : Information Technology in the Accounting Curriculum, International Education Guideline, December.

Education Committee of the International Federation of Accountants (IFAC) : (1995) Integrating Information Technology Across the Accounting Curriculum, The Experience of the Certified General Accountants' Association of Canada, December.

Australian Society of CPAs and Institute of Chartered Accountants in Australia : (1995) Guidelines for Joint Administration of Accreditation of Tertiary Courses by the Professional Accounting Bodies (Exposure Draft), October.

Joint Task Force of the Association for Information Systems, the Association for Computing Machinery and the Data Processing Management Association : (1995) Model Curriculum and Guidelines for Undergraduate Degree Programs in Information Systems (Draft Report), May.

\section{BIOGRAPHY}

Peter Juliff has been involved with the computing profession for approximately 30 years, most of them spent as an academic. He is the author of several books on computer science and software design and has presented courses on information systems and software development throughout Australia, Singapore, Malaysia and China. He is currently the Chair of IFIP Working Group WG3.4 and a Fellow of the Australian Computer Society. He currently holds the Chair in Management Information Systems at Deakin University in Melbourne, Australia. 